\title{
Newly recognized extratumoral features of colorectal cancer challenge the current tumor-node-metastasis staging system
}

\author{
Elias Athanasakis, Sofia Xenaki, Maria Venianaki, George Chalkiadakis, Emmanuel Chrysos \\ University Hospital of Heraklion Crete, Greece
}

\begin{abstract}
One of the most common malignant tumors in humans, colorectal cancer has been extensively studied during the past few decades. Staging colorectal cancer allows clinicians to obtain precise prognostic information and apply specific treatment procedures. Apart from remote metastases, the depth of tumor infiltration and lymph node involvement have traditionally been recognized as the most important factors predicting outcome. Variations in the molecular signature of colorectal cancer have also revealed differences in phenotypic aggressiveness and therapeutic response rates. This article presents a review of the extratumoral environment in colorectal surgery.
\end{abstract}

Keywords Colorectal cancer, tumor deposits, invasion, TNM staging, tumor budding

Ann Gastroenterol 2018; 31 (4): 1-10

\section{Introduction}

One of the most common malignant tumors in humans [1], colorectal cancer has been extensively studied during the past few decades. Staging colorectal cancer allows clinicians to obtain precise prognostic information and apply specific treatment regimens. The American Joint Committee on Cancer (AJCC)/ International Union Against Cancer (UICC) tumor-nodemetastasis (TNM) staging system serves as a useful tool for prediction of survival in colorectal cancer patients. Metastases, depth of tumor infiltration and lymph node involvement have traditionally been recognized as the most important factors predicting outcome [2,3]. Nevertheless, TNM staging occasionally fails in everyday clinical practice, as some patients in the same clinicopathological stage may exhibit noteworthy variation in outcomes [3], having greater recurrence and mortality rates than those justified by their TNM stage $[4,5]$. The fact that approximately $25 \%$ of early-stage colorectal cancer patients end up with distant metastases [6,7] has led to the hypothesis that cancer development and progression might depend partly on changes in several histological features with which we were not previously familiar. These previously unrecognized features are closely related to the way cancerous

Department of General Surgery, University Hospital of Heraklion Crete, Greece

Conflict of Interest:

Correspondence to: Emmanuel Chrysos, MD, PhD, FACS, Professor of Surgery, Department of General Surgery, University Hospital of Heraklion Crete, Greece, e-mail: manolischrysos@gmail.com

Received 2 January 2018; accepted 13 March 2018;

published online 19 June 2018

DOI: https://doi.org/10.20524/aog.2018.0284 cells interact with the surrounding stroma and obtain their potential for invasiveness [8]. They include tumor budding (TB), poorly differentiated clusters (PDCs), extramural vascular (vein) invasion (EMVI), perineural invasion (PNI), tumor deposits (TDs), and mucin pools (MPs) (Tables 1, 2).

TB

Originally described by Imai in the Japanese literature [9] as a "sprouting" at the invasive front of several carcinomas and subsequently defined by Jass in 1987 [10], TB represents both a morphological and a histological feature, which generally reflects the detachment of malignant tumor cells from the main tumor mass, resulting in the presence of individual or small clusters of up to five dedifferentiated cells within the peritumoral stroma $[11,12]$. This phenomenon, seen in approximately $40 \%$ of colorectal cancers $[13,14]$ and increasingly detected in advanced TNM stages [15] and poorly differentiated tumors $[12,16]$, is thought to be the consequence of the loss of adhesion of the tumor cells that produces cell migration at the invasive edge of the tumor, after disruption of the epithelial cell capsule $[7,16]$ (Table 1). Budding cells then invade and disrupt basic membrane and muscularis mucosae, thus allowing the development of metastases though lymphovascular invasion [17]. Interestingly, it seems that invasion by TB cells is facilitated by the arrest of the cell cycle, which allows cancer cells to focus on signals triggering local invasion rather than promoting proliferation [18].

Arguably [19], TB cells seem to obtain their growth potential through the process of epithelial-mesenchymal transition (EMT), believed to be a key process in the metastatic cascade $[16,20,21]$. EMT is described as a process during which a normal epithelial cell is transforming into a spindle cell, 
elongated and developing pseudopodia. This mesenchymal transformation results in a loss of expression of physiological membrane markers and an increase in invasiveness via elimination of membrane E-cadherin-mediated cell adhesion [22]. This allows cancer cells to detach from the main tumor mass and form buds into the peritumoral connective

Table 1 Frequency of appearance of extratumoral features in patients with colorectal cancer

\begin{tabular}{lc}
\hline Extratumoral features & Display frequency \\
\hline Tumor budding & $40 \%$ \\
\hline Poorly differentiated clusters & Less than $40 \%$ \\
Extramural vascular invasion & $11-90 \%$ \\
Perineural invasion & $7-32 \%$ \\
Tumor deposits & $4.5-45 \%$ \\
\hline Mucin pools & $15-35 \%$ \\
\hline
\end{tabular}

tissue $[13,23]$. The reduction in E-cadherin activity is closely related to the nuclear accumulation of beta-catenin, which prevents membrane E-cadherin functioning as a promoter of the cell-to-cell attachment process in TD cells [24,25]. Nuclear $\beta$-catenin accumulation has been linked with the risk of nodal involvement and poor prognosis in patients with colorectal cancers related to chromosomal (APC gene) mutation and Wnt-signaling pathway dysfunction $[26,27]$. On the other hand, nuclear $\beta$-catenin expression is rarely seen in high microsatellite instability (MSI-high) colorectal cancers [28]. As a result, membrane E-cadherin function and cell-to-cell adhesion are preserved; thus, MSI-high tumors are significantly less common to exhibit TB $[29,30]$.

TB can easily be detected using conventional hematoxylineosin stains at high magnification [23,31]. However, because tumor buds can be obscured by inflammation, immunohistochemical methods, such as pan-cytokeratin staining using anti-cytokeratin antibodies, are needed to properly identify budding cells $[19,31,32]$. Given adequate

Table 2 The impact of extratumoral features on the frequency of nodule invasion, local recurrence and survival rate

\begin{tabular}{|c|c|c|c|}
\hline $\begin{array}{l}\text { Extratumoral } \\
\text { features }\end{array}$ & Nodule invasion & Local recurrence & Survival rate \\
\hline TB & $\begin{array}{l}9.8-27 \% \text { risk of lymph node metastasis } \\
\text { Presence of }>10 \text { tumor buds seems } \\
\text { to be a powerful predictor of LN } \\
\text { involvement }\end{array}$ & $\begin{array}{l}\text { The more severe the intratumoral } \\
\text { budding, the higher the grade of } \\
\text { peritumoral budding } \\
\text { Development of an aggressive } \\
\text { invasive front linked to the } \\
\text { epithelial mesenchymal transition } \\
\text { process }\end{array}$ & $\begin{array}{l}\text { High-grade budding: } 39-67 \% \\
\text { cancer-specific 5-year SR and } 93.9 \% \\
\text { cumulative 5-year survival } \\
\text { Low-grade budding: } 80-90 \% \text { cancer } \\
\text { specific 5-year SR and } 73.9 \% \\
\text { cumulative 5-year survival }\end{array}$ \\
\hline PDCs & $\begin{array}{l}\text { Development of PDCs is related } \\
\text { to lymphatic infiltration and LN } \\
\text { metastasis, in otherwise node-negative } \\
\text { CC }\end{array}$ & $\begin{array}{l}\text { Development of an aggressive } \\
\text { invasive front linked to the } \\
\text { epithelial mesenchymal transition } \\
\text { process } \\
\text { Results in PNIs and EMVI }\end{array}$ & $\begin{array}{l}\text { DFS and OS are inversely related to } \\
\text { the number of PDC foci }\end{array}$ \\
\hline EMVI & $\begin{array}{l}\text { Strongly associated with the risk of } \\
\text { nodal involvement }\end{array}$ & $\begin{array}{l}\text { Invasion of a large }(>3 \mathrm{~mm}) \\
\text { extramural vein increases the risk } \\
\text { of metastases } \\
\text { Deterioration of tumor's } \\
\text { aggressiveness }\end{array}$ & $\begin{array}{l}\text { Invasion of }>4 \text { extramural veins results } \\
\text { in significant decline in } \mathrm{SR}\end{array}$ \\
\hline PNI & $\begin{array}{l}\text { High probability of lymphovascular } \\
\text { invasion }\end{array}$ & $\begin{array}{l}5 \text {-year local recurrence }>2.5 \text {-fold in } \\
\text { PNI-positive patients }\end{array}$ & $\begin{array}{l}\text { Dramatic reduction in SR - 3- or } \\
5 \text {-year DFS in PNI positive patients (as } \\
\text { low as a quarter of that compared to } \\
\text { the PNI-negative colorectal games) }\end{array}$ \\
\hline TDs & $\begin{array}{l}\text { Confusion distinguishing between TDs } \\
\text { and extracapsular LNs }\end{array}$ & $\begin{array}{l}\text { Presence of TDs increases the risk } \\
\text { of LR } \\
\text { TDs in stage II CC are associated } \\
\text { with a higher incidence than stage } \\
\text { III CC without TDs }\end{array}$ & $\begin{array}{l}\text { DFS and OS are significantly lower in } \\
\text { patients with TD-positive tumors }\end{array}$ \\
\hline MPs & No direct association & $\begin{array}{l}\text { No direct association } \\
\text { LR according to the response to } \\
\text { chemoradiotherapy }\end{array}$ & $\begin{array}{l}\text { Acellular MPs have no actual effect on } \\
\text { DFS and OS } \\
\text { Cellular MPs with detection of viable } \\
\text { malignant cells are associated with } \\
\text { a } 17.8 \% 5 \text {-year survival and a } 16.9 \% \\
10 \text {-year survival }\end{array}$ \\
\hline
\end{tabular}

SR, survival rate; $L N$, lymph node; TB, tumor budding; PDCs, poorly differentiated clusters; EMVI, extramural vascular invasion;

PNI, perineural vascular invasion; TDs, tumor deposits; MPs, mucin pools; DFS, disease free survival; OS, overall survival; CC, colorectal cancer; $L R$, local recurrence 
experience, interobserver agreement in detecting TB and EMT has been reported to range between $83-96 \%[31,33,34]$, although diagnostic methods need further standardization.

In clinical terms, the presence of TB has been proved to increase the risk of lymph node metastases, either in patients with malignant polyps or in those with proven stage II colorectal cancer, thus mandating changes in therapeutic practice [12]. In fact, there is a great body of evidence supporting the role of TB in predicting colorectal cancer aggressiveness, as it seems to be related with poorly differentiated tumors that have a roughly invasive front, which in turn gives rise to vascular and lymphatic invasion [35-37]. It is currently known that, among other factors, TB is strongly correlated with a 9.8$27 \%$ risk of lymph node metastases, in either stage I (early T1/2 N0 tumors) $[14,26,35,38-44]$ or stage II (T3/T4 N0 tumors) $[14,34,45]$ colorectal cancers. On the other hand, the number of tumor buds is related to the actual risk of development of lymph node metastases, since the presence of 10 or more tumor buds (high-grade budding) [34] seems to be a powerful predictor of lymph node involvement $[44,46]$. High-grade budding has been increasingly detected in poorly differentiated, serrated, BRAF-mutated colorectal tumors [47], which without exception present with poor prognosis.

The depth of infiltration by budding cells is currently shown to influence the frequency of lymph node metastases. Submucosal invasion $<1000 \mu \mathrm{m}(1 \mathrm{~mm})$ is related with a low risk for nodal metastases [35,40-42], irrespective of the budding grade. However, the risk of nodal involvement in tumors invading beyond $1000 \mu \mathrm{m}$ into submucosa ( $\geq \mathrm{sm} 2)$, is related to the grade of $\mathrm{TB}$, being exceptionally high in highgrade budding [44]. Following invasion of the submucosa, budding cells invade the muscularis propria either horizontally, spreading between circular and longitudinal muscle layers (expanding type), or "streaming" into the circular muscle layer (infiltrating type) $[8,48]$. Either invasion process is related to an increase in the risk of vascular and lymphatic infiltration [48]. Moreover, the horizontal spread of budding cells between circular and longitudinal muscle layers may facilitate perineural invasion in the myenteric plexus, thus providing an alternative way for the tumor to metastasize [48]. Similarly, tumor buds diffusely invading into the circular muscle layer could trigger stromal fibrosis and bowel wall shrinking. Indeed, obstructing carcinomas often present with high-grade infiltratingtype TB [49].

It has been repeatedly shown that the presence of severe budding increases the risk of locoregional recurrence and lowers the rates of both disease-free (DFS) and overall (OS) patient survival $[14,34,45,50,51]$. In fact, high-grade budding is associated with lower cancer-specific 5-year survival rates (ranging between 39\% and 67\%) compared with low-grade budding, related with survival rates ranging between $80 \%$ and $92 \%$ [34,52]. Similarly, cumulative 5-year survival is inversely related to the grade of budding (93.9\% in low vs. $73.9 \%$ in highgrade TB patients) [45].

TB-positive early colorectal cancer patients may present with nodal metastases and stage II colorectal cancer patients with high-grade TB experience similar or even worse outcomes and mortality rates compared to those with TB-negative stage
III colorectal cancer $[15,23,53]$. As a consequence, changes in therapeutic strategies must be strongly recommended. Local excision of a seemingly early-stage tumor and omission of adjuvant chemotherapy for an otherwise stage II cancer may be not oncologically sufficient $[34,38,40,44-46,50]$. On the contrary, detection of TB does not provide any additional information regarding outcome in node-positive stage III colorectal cancer patients, as they are almost always suitable candidates for (neo)-adjuvant (radio)-chemotherapy [54], although poor response rates should be anticipated in the presence of severe TB $[55,56]$.

Hypoperfusion of the TB area could be partly responsible for the resistance of high-grade budding tumors to chemotherapy $[55,56]$, as peritumoral stromal vessels surrounding tumor buds have a small perimeter and reduced lumen area compared to vessels located within the tumor center [57] and are thus susceptible to hypoxia [58].

Host immune defense mechanisms seem to play a significant role in reducing the detrimental effect of TB [23]. Peritumoral stromal infiltration by inflammatory cells has been found to limit the invasion of budding cells via cell-to-cell interaction, resulting in the immune destruction of the budding clusters $[13,59]$. This pro-/anti-tumor factors model seems to reliably predict outcomes in colorectal cancer patients, since patients with high-grade TB tumors have a considerably better prognosis under the presence of peritumoral inflammation, exhibiting lower rates of nodal involvement and better survival [13,59-61].

Apart from TB found in the periphery of the tumor mass in resection specimens, it is not unusual for tumor buds to be discovered within the tumor mass itself during preoperative colon and non-radiated rectum biopsies [33]. This so-called intratumoral budding is seen in approximately $17-20 \%$ of biopsy specimens [62]. The presence of intratumoral buds in colorectal cancer biopsies is actually related to the development of an aggressive invasive front, as indicated by the increase in peritumoral budding counts found in concomitant surgical specimens. That is, the more severe the intratumoral budding, the higher the grade of peritumoral budding. Intratumoral budding directly reflects the tumor's biological aggressiveness $[33,34,38,40,44-46,50]$, being associated with a significant reduction in DFS (33\% vs. $78 \%$ ), cancer-specific 5-year survival (61\% vs. $87 \%)$ and chemotherapy response rates [62] (Tables 1, 2).

\section{PDCs}

PDCs represent, by definition, groups of five or more dedifferentiated tumor cells with minimal or no glandular formation located at the peritumoral matrix close to the invasive edge $[63,64]$. It has been suggested that the formation of PDCs represents a sequential step in the growth process of the colorectal cancer, as they seem to develop through the formation of TB [64-66]. Indeed, PDC and TB share similar morphology, both appear at the tumor's invasive front and are linked to the EMT process [66]. 
PDCs are easily detected by the use of hematoxylin-eosin staining at the advancing edge of the tumor, with tumor cells being counted in the microscopic field under a $\times 20$ objective lens $[64,67,68]$. As PDC foci are larger than TB foci, unlike the latter they are easily identified without the application of cytokeratin-based immunohistochemistry [19]. According to the number of PDC foci identified at the part of the tumor's invasive site with the highest number of PDCs, a grading system has been developed to categorize colorectal cancer into three grades of malignancy. Grade 1 includes tumors with less than 5 PDC foci, grade 2 includes tumors with 5-9 PDC foci, and grade 3 includes tumors with 10 or more PDC foci $[64,67,69,70]$. It seems that the number of PDC foci provides higher accuracy and better reproducibility in colorectal cancer staging than the conventional TNM system [71,72].

Up to $40 \%$ of colorectal cancers may present with PDCs (Table 1). The incidence increases with the depth of tumor infiltration. Tumors invading beyond $1000 \mu \mathrm{m}$ into submucosa carry the highest risk. Rectal cancers seem to present preferentially with a PDC pattern $[63,64]$.

It has been suggested that, like TB, the development of PDCs is closely related to Wnt-signaling pathway dysfunction as a result of chromosomal mutation and is therefore associated with failure of the cell-to-cell adhesion process due to loss of membrane E-cadherin [64]. Furthermore, K-RAS mutations seem to be involved in the PDC formation process, as they are significantly related to PDC grade [73].

PDCs and the micropapillary pattern seen in several colorectal cancers are suspected to share the same biological basis [63] and occasionally display morphologic similarity. Indeed, although uncommonly seen in approximately $4-13 \%$ of colorectal cancers, a micropapillary component may be present over between $5-95 \%$ of their surface, located mostly at their invasive front [74,75]. The micropapillary component consists of clusters of cancer cells located within intra- or peritumoral empty spaces resembling (but not being) lymphatic vessels, lack a fibrovascular core and present reverse polarity, resulting in secretory activity in the stroma-facing surface [74]. When compared to those without, colorectal cancers with a micropapillary component exhibit aggressive biological behavior, as they have greater lymphatic metastatic potential [74,76], a higher risk of being unresectable [75] and significantly lower survival rates [74].

Several studies have documented the impact of PDCs on the risk of lymph node metastases and patient survival. The development of PDCs is undeniably related to lymphatic infiltration and lymph node metastases $[64,67,68]$, as well as occult lymph node micrometastases in otherwise nodenegative colorectal cancers $[63,68]$. The PDC pattern is also associated with perineural invasion $[64,67,77]$ and EMVI [64]. As a result, both, DFS and OS are greatly influenced by the presence of PDCs, being inversely related to the number of PDC foci $[64,67,69,70,72,77]$. Thus, the presence of PDCs may call for upstaging of stage I/II colorectal cancer patients, as many of them exhibit similar or even worse survival rates compared to stage III patients $[68,72]$. The grade of the PDC pattern also has a significant impact on the tumor's response to chemotherapy, as colorectal cancers with more than 10 PDC foci (grade 3 tumors), especially metastatic ones, show no significant post-chemotherapy benefit [70] (Tables 1,2).

\section{EMVI}

EMVI invasion, predominately venous, is thought to be a distinct predisposing factor leading to poor outcomes in colorectal cancer patients. It is defined as a rounded mass of tumor cells located in an endothelium-lined space that is surrounded by a smooth muscle layer and/or contains red blood cells [78]. Gastrointestinal pathologists are nowadays able to indirectly suspect or even diagnose the presence of venous invasion by detecting either a tumor mass, near or adjacent to an artery, without identification of an accompanying vein ("orphan" artery sign), or the presence of smooth tongues of tumor in the surrounding fat, the socalled "protruding tongue" sign $[3,79]$. However, diagnosing EMVI can occasionally prove very challenging, especially in the hands of non-specialized pathologists; thus, the reported incidence varies widely between $11 \%$ and $90 \%$, suggesting that EMVI is underreported worldwide [79-81] (Table 1). The use of elastin-staining techniques that differentiate veins from lymphatic vessels by highlighting the elastic fibers in the wall of the former, have added significant advantage in diagnosing vascular invasion by increasing the sensitivity of detecting EMVI more than twofold $[79,82,83]$, thus improving interobserver agreement significantly. Immunohistochemistry often fails to detect EMVI, as the endothelium of the affected veins is frequently completely destroyed.

Apart from the biopsy specimen, vascular invasion can and should be detected preoperatively, during the tumorstaging procedure, as it is considered a risk factor for an adverse outcome. Magnetic resonance imaging (MRI) is the only imaging modality that can reliably achieve an accurate diagnosis of vascular invasion (especially extramural), exhibiting significant sensitivity in detecting venous infiltration into the mesorectum $[81,84,85]$. Recently, MRI was proved to have acceptable sensitivity in detecting EMVI during local staging of colon cancer [86].

Vascular invasion can also be intramural, as a result of tumor invasion into the submucosa and the wall's muscular layer [87]. On the other hand, invasion of the extramural veins seems to be associated with the processes taking place at the invasive edge of the tumor, as it is apparently related to the development of TB. Budding cells may independently invade vessels remote from the tumor itself, giving rise to the EMVI [36]. Because of the sequential nature of the tumor development process, intramural and extramural vascular invasion are almost always detected simultaneously [87].

The clinical significance of intramural vascular invasion is not well established and is consequently controversial, although its presence seems to increase the risk of development of distant metastases [87]. However, EMVI is undeniably a strong predictor of a poor outcome in colorectal cancer patients. It has been repeatedly shown that the presence of EMVI is strongly associated with a greater risk of nodal involvement [80,81], an 
increase in the incidence of distant metastases, either during diagnosis or during postoperative follow up [81], a greater recurrence rate [82] and lower survival rates [80,82,84,87]. Invasion of a large ( $>3 \mathrm{~mm}$ ) extramural vein seems to increase the risk for metastases significantly [85], while the presence of more than four invaded extramural veins is associated with a significant decline in survival rates [82].

Similarly to TB and PDCs, the presence of EMVI is associated with tumor aggressiveness. As a consequence, detection of EMVI in early-stage colorectal cancer patients might serve as an indicator of the need for administration of chemotherapy [88]. On the other hand, persistent EMVI positivity following neoadjuvant therapy is related to a poor outcome in colorectal cancer patients. In that case, patients may obtain survival benefit from the use of adjuvant therapy, as it has been shown that both the risk of recurrence and DFS are improved following administration of adjuvant chemotherapy [89] (Tables 1,2).

\section{PNI}

PNI provides a distinct way for the colorectal cancer to spread. Having been correlated with an aggressive cancerous phenotype [90], PNI is a process during which tumor cells invade nervous structures and spread further along nerve sheaths through a complex mechanism that involves a neurotropic factor-mediated tumor-matrix interaction [91]. This process may be greatly facilitated by the presence of budding cells that can infiltrate the myenteric plexus and then spread into the perineurium [48]. Alternatively, it has been proposed that PNI could be the result of stimulation of cancer cell growth by nerves that infiltrate the peritumoral matrix [92]. Extramural PNI has been recognized as a factor that enhances the tumor's metastatic potential. The clear association between extramural PNI and the presence or development of colorectal cancer liver metastases can be explained by the fact that both the colon and the liver share a sympathetic fiber network of common preganglionic origin, thus allowing the malignant cells to metastasize from the original tumor site toward the liver through sympathetic nerves and without invasion of the surrounding structures [93].

The true incidence of PNI in colorectal cancer is largely unknown, because it is consistently underreported. Using anti-S100 antibody-based immunohistochemistry techniques, pathologists are now able to diagnose significantly more cases of PNI-positive colorectal cancers, thus enhancing interobserver agreement [94]. The reported incidence varies widely between approximately $7 \%$ and 32\% [92,95-97] (Table 1).

The deeper the tumor invasion, the greater the number of circumferential resection margins involved, the greater the stage of the disease and/or the lower the tumor differentiation, the higher the incidence of PNI [97]. Tumors located in the retroperitonealized segments (ascending and descending colon cancers) have a higher incidence of PNI, possibly because of their anatomical proximity to the retroperitoneal autonomic nerve plexus [91,93].
Several studies confirm the high probability of lymphovascular invasion and consequently lymph node metastases in PNI-positive tumors $[98,99]$. Thus, identification of PNI in early stage I/II colorectal cancer may call for changes in the therapeutic approach to those patients, indicating the need for post-surgery chemotherapy $[98,100]$.

The presence of PNI strongly influences the local recurrence rate in patients operated for colorectal cancer. It has been estimated that the 5-year local recurrence rate can be 2.5 -fold or even higher in PNI-positive compared with PNI-negative patients [101]. Consequently, adjuvant chemotherapy might be considered as a means of reducing the risk of local recurrence in those patients $[96,101]$.

There is global agreement that the presence of PNI causes a dramatic reduction in survival rates, irrespective of the presence of other adverse factors. Five- or 3-year DFS in patients with PNIpositive tumors has been found to be as low as a quarter of that in patients with PNI-negative colorectal games [90,97,98,101,102]. Likewise, OS has also been shown to be significantly lower in PNI-positive tumors [90,94,95,97,98,101,102]. There is evidence indicating that the presence of PNI in early (stage I/ II) colorectal cancer patients reduces survival rates to levels equal to or even below those observed in stage III node-positive colorectal cancer patients [102].

Although official recommendations cannot be made yet since PNI is not included in the currently used staging systems, administration of adjuvant chemotherapy might be a good option in PNI-positive patients. Postoperative chemotherapy should also be offered in post-neoadjuvant therapy PNIpositive patients, irrespectively of the tumor regression grade achieved [103] (Tables 1, 2).

\section{TDs}

TDs have been considered as extramural focal aggregates of cancer cells located in the peritumoral fatty tissue (either mesocolon or mesorectum), which have no continuity with the main tumor mass and are not associated with a lymph node $[104,105]$. Historically, the exact definition of TDs has changed several times, with AJCC/UICC TNM5 classifying them in the $\mathrm{T}$ category as discontinuous tumor extensions if their size is less than $3 \mathrm{~mm}$ in diameter $[105,106]$ and AJCC/ UICC TNM6 defining them as extratumoral nodules with irregular contours, as opposed to the smooth round surface of the involved regional lymph nodes (N category) [105,107]. Because previous definitions were based on weak and unsubstantiated data [108], AJCC/UICC TNM7 and TNM8 incorporate TDs into a new $\mathrm{N}$ category (N1c), defining them as any cancerous nodule, either microscopic or macroscopic, located in the lymph drainage area of the peritumoral fatty tissue, irrespective of size or shape, as long as there is histologically proven absence of both residual lymphatic tissue in the nodule and regional lymph node metastasis (N0) [105,108,109]. Of course, there is always a possibility for a nodule diagnosed as a TD to be simply a completely infiltrated lymph node in which no normal lymphatic parenchyma remains [104]. 
However, there is still argument about what TDs really are, as they usually share different morphology that makes their origin unclear $[110,111]$. Some believe that TDs simply represent a stage of the lymphovascular and/or perineural invasion process during which malignant cells begin to proliferate, giving rise to distinct nodules of cancer [112] that have to be distinguished from involved lymph nodes. It has been suggested that the presence of a round shape, lymphoid follicles, peripheral lymphocyte rim, subcapsular sinus, thick capsule and lymph nodes in the surrounding fatty tissue indicates the diagnosis of lymph node rather than TD [110]. There are several reports suggesting different groupings and definitions for TDs, generally classifying them as either lymphovascular, perineural or nodular type [104,105,112,113].

TDs are generally present in about $4.5-45 \%$ of colorectal cancer patients $[104,105,108,111-118]$, while their incidence seems to be greater in advanced and/or metastatic tumors [104,105,119] (Table 1). Tumor deposits are more commonly found in colorectal cancers with poor differentiation [115], involved lymph nodes [104,105,111,119], EMVI [104,111,117], PNI [95,104,115,119], and distant metastases [119].

The reported incidence varies because of the use of different staging systems during the past two decades. Indeed, it has recently been shown that, in $5^{\text {th }}$ and $6^{\text {th }}$ editions of the AJCC/ UICC TNM staging system, the number of involved lymph nodes was significantly overestimated, since many of these nodules were classified as TDs in AJCC/UICC TNM7. As a consequence, the number of cases with TDs and a number of lymph nodes below 12 was significantly increased by the use of TNM7 staging, thus calling into question the accuracy of TNM5/6 lymph node staging [120]. Furthermore, differences in defining TDs have led to significant changes in staging colorectal cancer patients, as the use of different TNM staging systems may cause stage migration of as much as $64 \%$ in those with TD $[110,121]$. Interestingly, despite the fact that TNM7 included the N1c category in an effort to collect enough data to guide future staging systems providing evidence for the significance of TDs, there are currently suggestions about reclassifying TD-positive tumors as metastatic ones (M1) [122]. However, several authors have presented arguments regarding the clinical utility of TNM7 staging, claiming that counting TDs as involved lymph nodes provides better prognostic and predictive value [116]. It is well known that a one-node change in the total number of involved lymph nodes can alter the staging of colorectal cancer disease and may have significant prognostic implications [110]. Nevertheless, the usual practice nowadays is to assess the presence of TDs only in node-negative colorectal cancer patients and not to add the number of TDs to the involved nodes in stage III patients.

Although both are related to poor prognosis, TDs must be distinguished from extracapsular lymph node invasion, which has not yet been accepted as a tumor staging factor [123]. The distinction between them is usually easy to determine since, by definition, the absence of lymph node tissue is a prerequisite for the diagnosis of TDs. As a consequence, TDs and extracapsular lymph node invasion are rarely seen simultaneously [124].

The presence of TDs has been shown to correlate with an increase in the risk of local recurrence, either before [104,105] or after [114] administration of neoadjuvant therapy. Detection of TDs, especially those with irregular shape, in stage II colorectal cancers is associated with a higher incidence of local recurrence compared to stage III tumors without TDs [104].

BothDFS[95,112,115,117-119] andOS[95,105,108,111,117-120] are significantly lower in patients with TD-positive tumors. Moreover, the absolute number and size of TDs seems to affect DFS and OS rates disproportionally [112,122].

Given the great impact of TDs on the prognosis of the colorectal cancer patient, it has been suggested that their detection is necessary for correct staging of the disease, so that TD-positive tumors may be treated with (neo)adjuvant (radio) chemotherapy. Indeed, significant benefits have been reported in early-stage TD-positive colorectal cancer patients, who otherwise would not be offered (radio)chemotherapy [104]. However, there is still argument regarding the clinical use of the presence of TD-like peritumoral nodules following neoadjuvant therapy, as they may simply represent residual tumor microfoci, indicating a good tumor regression grade, rather than real TDs [108] (Tables 1,2).

\section{MPs}

MPs represent aggregations of mucus occasionally seen after neoadjuvant chemoradiotherapy in rectal cancer surgical specimens. The incidence of MPs found in postchemoradiotherapy surgical specimens from rectal cancer patients varies between approximately 15\% and 35\% [125-127] (Table 1). Studies referring to both acellular and cellular MPs report that the two types have approximately equal incidence $[125,127]$.

Although the presence of cellular MPs has been reported to correlate with worse tumor differentiation [126], acellular MPs seem to have no significant impact on the rectal cancer patient's outcome, provided that complete pathological response to neoadjuvant therapy has been achieved. In fact, neither DFS nor OS differ significantly between rectal cancer patients with or without the presence of MPs in their cancerfree surgical specimens [126-128]. However, detection of viable malignant cells within the MPs is reported to be associated with a $17.8 \%$ and $16.9 \%$ decrease in 5- and 10-year survivals respectively [125] (Tables 1,2).

According to all the above, it is likely that ever-evolving cancer staging systems are nowadays interested in limiting their dependency on the grossly apparent surgical findings to accurately stage colorectal cancer. Instead, they increasingly use histopathologic and immunohistochemical data to precisely detect the severity of the disease and to determine the appropriate treatment accordingly. For that reason, in clinical practice, the identification of TB, PDCs, EMVI, PNI, and TDs needs to be part of the pathological report, since their presence may call for changes in the therapeutic approach. In those cases, clinicians should be aware of the risk of their patients being undertreated if a conventional staging system is used. Accordingly, colorectal cancer patients should be informed about the potential risk of having a poor outcome by choosing minor treatment for an otherwise apparently minor disease. 


\section{References}

1. Greenlee RT, Hill-Harmon MB, Murray T, Thun M. Cancer statistics, 2001. CA Cancer J Clin 2001;51:15-36.

2. Ohtsuki K, Koyama F, Tamura T, et al. Prognostic value of immunohistochemical analysis of tumor budding in colorectal carcinoma. Anticancer Res 2008;28:1831-1836.

3. Maguire A, Sheahan K. Controversies in the pathological assessment of colorectal cancer. World $J$ Gastroenterol 2014;20:9850-9861.

4. Puppa G, Sonzogni A, Colombari R, Pelosi G. TNM staging system of colorectal carcinoma: a critical appraisal of challenging issues. Arch Pathol Lab Med 2010;134:837-852.

5. Lyall MS, Dundas SR, Curran S, Murray GI. Profiling markers of prognosis in colorectal cancer. Clin Cancer Res 2006;12:1184-1191.

6. Labianca R, Merelli B. Screening and diagnosis for colorectal cancer: present and future. Tumori 2010;96:889-901.

7. Glimelius B, Cavalli-Björkman N. Metastatic colorectal cancer: current treatment and future options for improved survival. Medical approach-present status. Scand J Gastroenterol 2012;47:296-314.

8. Grizzi F, Celesti G, Basso G, Laghi L. Tumor budding as a potential histopathological biomarker in colorectal cancer: Hype or hope? World J Gastroenterol 2012;18:6532-6536.

9. Imai T. The growth of human carcinoma: a morphological analysis. Fukuoka Igaku Zasshi 1954;45:30.

10. Jass JR, Love SB, Northover JM. A new prognostic classification of rectal cancer. Lancet 1987;1:1303-1306.

11. De Smedt L, Palmans S, Sagaert X. Tumour budding in colorectal cancer: what do we know and what can we do? Virchows Arch 2016;468:397-408.

12. Koelzer VH, Zlobec I, Lugli A. Tumor budding in colorectal cancer-ready for diagnostic practice? Hum Pathol 2016;47:4-19.

13. Zlobec I, Lugli A, Baker K, et al. Role of APAF-1, E-cadherin and peritumoral lymphocytic infiltration in tumour budding in colorectal cancer. J Pathol 2007;212:260-268.

14. Rogers AC, Winter DC, Heeney A, et al. Systematic review and meta-analysis of the impact of tumour budding in colorectal cancer. Br J Cancer 2016;115:831-840.

15. Hase K, Shatney C, Johnson D, Trollope M, Vierra M. Prognostic value of tumor "budding" in patients with colorectal cancer. Dis Colon Rectum 1993;36:627-635.

16. Grigore AD, Jolly MK, Jia D, Farach-Carson MC, Levine $\mathrm{H}$. Tumor budding: The name is EMT. Partial EMT. J Clin Med 2016;5:51.

17. Hagedorn EJ, Sherwood DR. Cell invasion through basement membrane: the anchor cell breaches the barrier. Curr Opin Cell Biol 2011;23:589-596.

18. Rubio CA. Arrest of cell proliferation in budding tumor cells ahead of the invading edge of colonic carcinomas. A preliminary report. Anticancer Res 2008;28:2417-2420.

19. Yamada N, Sugai T, Eizuka M, et al. Tumor budding at the invasive front of colorectal cancer may not be associated with the epithelial mesenchymal transition. Hum Pathol 2017;60:151-159.

20. Bhangu A, Wood G, Mirnezami A, Darzi A, Tekkis P, Goldin R. Epithelial mesenchymal transition in colorectal cancer: Seminal role in promoting disease progression and resistance to neoadjuvant therapy. Surg Oncol 2012;21:316-323.

21. Gurzu S, Silveanu C, Fetyko A, Butiurca V, Kovacs Z, Jung I. Systematic review of the old and new concepts in the epithelial-mesenchymal transition of colorectal cancer. World $J$ Gastroenterol 2016;22:6764-6775

22. Kalluri R. EMT: when epithelial cells decide to become mesenchymal-like cells. J Clin Invest 2009;1 19:1417-1419.

23. Lugli A, Karamitopoulou E, Zlobec I. Tumour budding: a promising parameter in colorectal cancer. $\mathrm{Br} J$ Cancer 2012;106:1713-1717.

24. El-Bahrawy MA, Poulsom R, Jeffery R, Talbot I, Alison MR. The expression of E-cadherin and catenins in sporadic colorectal carcinoma. Hum Pathol 2001;32:1216-1224.

25. García-Solano J, Conesa-Zamora P, Trujillo-Santos J, Torres-Moreno D, Mäkinen MJ, Pérez-Guillermo M. Immunohistochemical expression profile of $\beta$-catenin, E-cadherin, P-cadherin, laminin-5 $\gamma 2$ chain, and SMAD4 in colorectal serrated adenocarcinoma. Hum Pathol 2012;43:10941102.

26. Umemura K, Takagi S, Shimada T, et al. Prognostic and diagnostic significance of tumor budding associated with $\beta$-catenin expression in submucosal invasive colorectal carcinoma. Tohoku J Exp Med 2013;229:53-59.

27. Jass JR, Barker M, Fraser L, et al. APC mutation and tumour budding in colorectal cancer. J Clin Pathol 2003;56:69-73.

28. Zlobec I, Bihl MP, Foerster A, Rufle A, Lugli A. The impact of CpG island methylator phenotype and microsatellite instability on tumour budding in colorectal cancer. Histopathology 2012;61:777-787.

29. Andersen HS, Bertelsen CA, Henriksen R, et al. The pathologic phenotype of colon cancer with microsatellite instability. Dan Med J 2016;63:A5198

30. Saridaki Z, Souglakos J, Georgoulias V. Prognostic and predictive significance of MSI in stages II/III colon cancer. World J Gastroenterol 2014;20:6809-6814.

31. Horcic M, Koelzer VH, Karamitopoulou E, et al. Tumor budding score based on 10 high-power fields is a promising basis for a standardized prognostic scoring system in stage II colorectal cancer. Hum Pathol 2013;44:697-705.

32. Satoh K, Nimura S, Aoki M, et al. Tumor budding in colorectal carcinoma assessed by cytokeratin immunostaining and budding areas: possible involvement of c-Met. Cancer Sci 2014;105:1487-1495.

33. Zlobec I, Hädrich $\mathrm{M}$, Dawson $\mathrm{H}$, et al. Intratumoural budding (ITB) in preoperative biopsies predicts the presence of lymph node and distant metastases in colon and rectal cancer patients. Br J Cancer 2014;110:1008-1013.

34. Lai YH, Wu LC, Li PS, et al. Tumour budding is a reproducible index for risk stratification of patients with stage II colon cancer Colorectal Dis 2014;16:259-264.

35. Beaton C, Twine CP, Williams GL, Radcliffe AG. Systematic review and meta-analysis of histopathological factors influencing the risk of lymph node metastasis in early colorectal cancer. Colorectal Dis 2013;15:788-797.

36. Bayar S, Saxena R, Emir B, Salem RR. Venous invasion may predict lymph node metastasis in early rectal cancer. Eur J Surg Oncol 2002;28:413-417.

37. Wada $\mathrm{H}$, Shiozawa $\mathrm{M}$, Sugano $\mathrm{N}$, et al. Lymphatic invasion identified with D2-40 immunostaining as a risk factor of nodal metastasis in $\mathrm{T} 1$ colorectal cancer. Int J Clin Oncol 2013;18:1025-1031.

38. Homma Y, Hamano T, Otsuki Y, Shimizu S, Kobayashi H, Kobayashi Y. Severe tumor budding is a risk factor for lateral lymph node metastasis in early rectal cancers. J Surg Oncol 2010;102:230-234.

39. Tateishi Y, Nakanishi Y, Taniguchi H, Shimoda T, Umemura S. Pathological prognostic factors predicting lymph node metastasis in submucosal invasive (T1) colorectal carcinoma. Mod Pathol 2010;23:1068-1072.

40. Mou S, Soetikno R, Shimoda T, Rouse R, Kaltenbach T. Pathologic predictive factors for lymph node metastasis in submucosal invasive (T1) colorectal cancer: a systematic review and metaanalysis. Surg Endosc 2013;27:2692-2703.

41. Bosch SL, Teerenstra S, de Wilt JH, Cunningham C, Nagtegaal 
ID. Predicting lymph node metastasis in pT1 colorectal cancer: a systematic review of risk factors providing rationale for therapy decisions. Endoscopy 2013;45:827-834.

42. Resch A, Langner C. Risk assessment in early colorectal cancer: histological and molecular markers. Dig Dis 2015;33:77-85.

43. Wada H, Shiozawa M, Katayama K, et al. Systematic review and meta-analysis of histopathological predictive factors for lymph node metastasis in T1 colorectal cancer. J Gastroenterol 2015;50:727-734.

44. Kawachi H, Eishi $\mathrm{Y}$, Ueno $\mathrm{H}$, et al. A three-tier classification system based on the depth of submucosal invasion and budding/sprouting can improve the treatment strategy for T1 colorectal cancer: a retrospective multicenter study. Mod Pathol 2015;28:872-879.

45. Betge J, Kornprat P, Pollheimer MJ, et al. Tumor budding is an independent predictor of outcome in AJCC/UICC stage II colorectal cancer. Ann Surg Oncol 2012;19:3706-3712.

46. Masaki T, Matsuoka H, Sugiyama M, Abe N, Sakamoto A, Atomi Y. Actual number of tumor budding as a new tool for the individualization of treatment of T1 colorectal carcinomas. J Gastroenterol Hepatol 2006;21:1115-1121.

47. García-Solano J, Conesa-Zamora P, Trujillo-Santos J, Mäkinen MJ, Pérez-Guillermo M. Tumour budding and other prognostic pathological features at invasive margins in serrated colorectal adenocarcinoma: a comparative study with conventional carcinoma. Histopathology 2011;59:1046-1056.

48. Ueno $\mathrm{H}$, Hase $\mathrm{K}$, Hashiguchi $\mathrm{Y}$, et al. Growth pattern in the muscular layer reflects the biological behaviour of colorectal cancer. Colorectal Dis 2009;11:951-959.

49. Xu CJ, Mikami T, Nakamura $\mathrm{T}$, et al. Tumor budding, myofibroblast proliferation, and fibrosis in obstructing colon carcinoma: the roles of Hsp47 and basic fibroblast growth factor. Pathol Res Pract 2013;209:69-74.

50. Petrelli F, Pezzica E, Cabiddu M, et al. Tumour budding and survival in stage II colorectal cancer: a systematic review and pooled analysis. J Gastrointest Cancer 2015;46:212-218.

51. van Wyk HC, Park J, Roxburgh C, Horgan P, Foulis A, McMillan DC. The role of tumour budding in predicting survival in patients with primary operable colorectal cancer: a systematic review. Cancer Treat Rev 2015;41:151-159.

52. van Wyk HC, Park JH, Edwards J, Horgan PG, McMillan DC, Going JJ. The relationship between tumour budding, the tumour microenvironment and survival in patients with primary operable colorectal cancer. Br J Cancer 2016;115:156-163.

53. Okuyama T, Nakamura T, Yamaguchi M. Budding is useful to select high-risk patients in stage II well-differentiated or moderately differentiated colon adenocarcinoma. Dis Colon Rectum 2003;48:1400-1406

54. Sy J, Fung CL, Dent OF, Chapuis PH, Bokey L, Chan C. Tumor budding and survival after potentially curative resection of nodepositive colon cancer. Dis Colon Rectum 2010;53:301-307.

55. Zlobec I, Molinari F, Martin V, et al. Tumor budding predicts response to anti-EGFR therapies in metastatic colorectal cancer patients. World J Gastroenterol 2010;16:4823-4831.

56. Tatsumi S, Matsuoka H, Hashimoto Y, Hatta K, Maeda K, Kamoshida S. Organic cation transporter 2 and tumor budding as independent prognostic factors in metastatic colorectal cancer patients treated with oxaliplatin-based chemotherapy. Int J Clin Exp Pathol 2014;7:204-212.

57. Mezheyeuski A, Nerovnya A, Bich T, Tur G, Ostman A, Portyanko A. Inter- and intra-tumoral relationships between vasculature characteristics, GLUT1 and budding in colorectal carcinoma. Histol Histopathol 2015;30:1203-1211.

58. Righi A, Sarotto I, Casorzo L, Cavalchini S, Frangipane E, Risio M. Tumour budding is associated with hypoxia at the advancing front of colorectal cancer. Histopathology 2015;66:982-990.
59. Koelzer VH, Canonica K, Dawson $\mathrm{H}$, et al. Phenotyping of tumor-associated macrophages in colorectal cancer: impact on single cell invasion (tumor budding) and clinicopathological outcome. Oncoimmunology 2016;5:e1106677.

60. Lugli A, Karamitopoulou E, Panayiotides I, et al. CD8+ lymphocytes/tumour-budding index: an independent prognostic factor representing a 'pro-/anti-tumour' approach to tumour host interaction in colorectal cancer. Br J Cancer 2009;101:13821392.

61. Max N, Harbaum L, Pollheimer MJ, Lindtner RA, Kornprat P, Langner C. Tumour budding with and without admixed inflammation: two different sides of the same coin? Br J Cancer 2016;114:368-371.

62. Rogers AC, Gibbons D, Hanly AM, et al. Prognostic significance of tumor budding in rectal cancer biopsies before neoadjuvant therapy. Mod Pathol 2014;27:156-162.

63. Barresi V, Branca G, Vitarelli E, Tuccari G. Micropapillary pattern and poorly differentiated clusters represent the same biological phenomenon in colorectal cancer: a proposal for a change in terminology. Am J Clin Pathol 2014;142:375-383.

64. Reggiani Bonetti L, Barresi V, Bettelli S, Domati F, Palmiere C. Poorly differentiated clusters (PDC) in colorectal cancer: what is and ought to be known. Diagn Pathol 2016;11:31.

65. Friedl P, Wolf K. Tumour-cell invasion and migration: diversity and escape mechanisms. Nat Rev Cancer 2003;3:362-374.

66. Karagiannis GS, Poutahidis T, Erdman SE, Kirsch R, Riddell RH, Diamandis EP. Cancer-associated fibroblasts drive the progression of metastasis through both paracrine and mechanical pressure on cancer tissue. Mol Cancer Res 2012;10:1403-1418.

67. Kinoshita O, Kishimoto M, Murayama Y, et al. Poorly differentiated clusters with larger extents have a greater impact on survival: a semi-quantitative pathological evaluation for 239 patients with non-mucinous pT2-3 colorectal carcinoma. World J Surg Oncol 2015;13:140.

68. Kinoshita O, Kishimoto M, Murayama Y, et al. The number of metastatic lymph nodes exhibiting poorly differentiated clusters predicts survival in patients with pStage III colorectal cancer. Int J Colorectal Dis 2016;31:283-290.

69. Kim JW, Shin MK, Kim BC. Clinicopathologic impacts of poorly differentiated cluster-based grading system in colorectal carcinoma. J Korean Med Sci 2015;30:16-23.

70. Tajima Y, Shimada Y, Kameyama H, et al. Association between poorly differentiated clusters and efficacy of 5-fluorouracil-based adjuvant chemotherapy in stage III colorectal cancer. Jpn J Clin Oncol 2017;47:313-320.

71. Barresi V, Reggiani Bonetti L, Branca G, Di Gregorio C, Ponz de Leon M, Tuccari G. Colorectal carcinoma grading by quantifying poorly differentiated cell clusters is more reproducible and provides more robust prognostic information than conventional grading. Virchows Arch 2012;461:621-628.

72. Barresi V, Reggiani Bonetti L, Ieni A, Domati F, Tuccari G. Prognostic significance of grading based on the counting of poorly differentiated clusters in colorectal mucinous adenocarcinoma. Hum Pathol 2015;46:1722-1729.

73. Bonetti R, Barresi V, Bettelli S, Caprera C, Manfredini S, Maiorana A. Analysis of KRAS, NRAS, PIK3CA and BRAF mutational profile in poorly differentiated clusters (PDC) of KRAS mutated colon cancer. Hum Pathol 2017;62:91-98.

74. Jakubowska K, Guzińska-Ustymowicz K, Pryczynicz A. Invasive micropapillary component and its clinico-histopathological significance in patients with colorectal cancer. Oncol Lett 2016;12:1154-1158.

75. Akimoto N, Fujimori T, Mitomi H, et al. Micropapillary pattern at the invasive front and its association with unresectable colorectal carcinomas. Dis Markers 2013;35:451-455.

76. Haupt B, Ro JY, Schwartz MR, Shen SS. Colorectal 
adenocarcinoma with micropapillary pattern and its association with lymph node metastasis. Mod Pathol 2007;20:729-733.

77. Yang M, Rehman AU, Zuo C, et al. A novel histologic grading scheme based on poorly differentiated clusters is applicable to treated rectal cancer and is associated with established histopathological prognosticators. Cancer Med 2016;5:15101518.

78. Talbot IC, Ritchie S, Leighton MH, Hughes AO, Bussey HJ, Morson BC. The clinical significance of invasion of veins by rectal cancer. Br J Surg 1980;67:439-442.

79. Kirsch R, Messenger DE, Riddell RH, et al. Venous invasion in colorectal cancer: impact of an elastin stain on detection and interobserver agreement among gastrointestinal and nongastrointestinal pathologists. Am J Surg Pathol 2013;37:200-210.

80. Chand M, Siddiqui MR, Swift I, Brown G. Systematic review of prognostic importance of extramural venous invasion in rectal cancer. World J Gastroenterol 2016;22:1721-1726.

81. Siddiqui MRS, Simillis C, Hunter C, et al. A meta-analysis comparing the risk of metastases in patients with rectal cancer and MRI-detected extramural vascular invasion (mrEMVI) vs mrEMVI-negative cases. Br J Cancer 2017;1 16:1513-1519.

82. Sato T, Ueno H, Mochizuki $\mathrm{H}$, et al. Objective criteria for the grading of venous invasion in colorectal cancer. Am J Surg Pathol 2010;34:454-462.

83. Howlett CJ, Tweedie EJ, Driman DK. Use of an elastic stain to show venous invasion in colorectal carcinoma: a simple technique for detection of an important prognostic factor. J Clin Pathol 2009;62:1021-1025.

84. Yu J, Huang DY, Xu HX, Li Y, Xu Q. Correlation between magnetic resonance imaging-based evaluation of extramural vascular invasion and prognostic parameters of T3 stage rectal cancer. J Comput Assist Tomogr 2016;40:537-542.

85. Sohn B, Lim JS, Kim H, et al. MRI-detected extramural vascular invasion is an independent prognostic factor for synchronous metastasis in patients with rectal cancer. Eur Radiol 2015;25:1347-1355

86. Nerad E, Lambregts DMJ, Kersten ELJ, et al. MRI for local staging of colon cancer: can MRI become the optimal staging modality for patients with colon cancer? Dis Colon Rectum 2017;60:385392.

87. Gibson KM, Chan C, Chapuis PH, Dent OF, Bokey L. Mural and extramural venous invasion and prognosis in colorectal cancer. Dis Colon Rectum 2014;57:916-926.

88. Chand M, Swift RI, Chau I, Heald RJ, Tekkis PP, Brown G. Adjuvant therapy decisions based on magnetic resonance imaging of extramural venous invasion and other prognostic factors in colorectal cancer. Ann R Coll Surg Engl 2014;96:543546.

89. Chand M, Rasheed S, Heald R, et al. Adjuvant chemotherapy may improve disease-free survival in patients with rectal cancer positive for MRI-detected extramural venous invasion following chemoradiation. Colorectal Dis 2017;19:537-543.

90. Poeschl EM, Pollheimer MJ, Kornprat P, et al. Perineural invasion: correlation with aggressive phenotype and independent prognostic variable in both colon and rectum cancer. J Clin Oncol 2010;28:e358-e360.

91. Liebig C, Ayala G, Wilks JA, Berger DH, Albo D. Perineural invasion in cancer: a review of the literature. Cancer 2009;115:3379-3391.

92. Van Wyx HC, Going J, Horgan P, McMillan DC. The role of perineural invasion in predicting survival in patients with primary operable colorectal cancer: a systematic review. Crit Rev Oncol Hematol 2017;112:11-20.

93. McCuskey RS. Anatomy of efferent hepatic nerves. Anat Rec A Discov Mol Cell Evol Biol 2004;280:821-826.
94. Shimada Y, Kido T, Kameyama H, et al. Clinical significance of perineural invasion diagnosed by immunohistochemistry with anti-S100 antibody in Stage I-III colorectal cancer. Surg Today 2015;45:1493-1500.

95. Mayo E, Llanos AA, Yi X, Duan SZ, Zhang L. Prognostic value of tumour deposit and perineural invasion status in colorectal cancer patients: a SEER-based population study. Histopathology 2016;69:230-238.

96. Nikberg M, Chabok A, Letocha H, Kindler C, Glimelius B, Smedh K. Lymphovascular and perineural invasion in stage II rectal cancer: a report from the Swedish colorectal cancer registry. Acta Oncol 2016;55:1418-1424.

97. Alotaibi AM, Lee JL, Kim J, et al. Prognostic and oncologic significance of perineural invasion in sporadic colorectal cancer. Ann Surg Oncol 2017;24:1626-1634.

98. Huh JW, Kim HR, Kim YJ. Lymphovascular or perineural invasion may predict lymph node metastasis in patients with $\mathrm{T} 1$ and T2 colorectal cancer. J Gastrointest Surg 2010;14:1074-1080.

99. Betge J, Pollheimer MJ, Kornprat P, Rehak P, Vieth M, Langner C. Perineural invasion is a strong and independent predictor of lymph node involvement in colorectal cancer. Dis Colon Rectum 2011;54:e273.

100. Xu B, Yu L, Zhao LZ, Ma DW. Prognostic factors in the patients with T2N0M0 colorectal cancer. World J Surg Oncol 2016;14:76.

101. Knijn N, Mogk SC, Teerenstra S, Simmer F, Nagtegaal ID. Perineural invasion is a strong prognostic factor in colorectal cancer: a systematic review. Am J Surg Pathol 2016;40:103-112.

102. Yang Y, Huang X, Sun J, et al. Prognostic value of perineural invasion in colorectal cancer: a meta-analysis. J Gastrointest Surg 2015; 19:1113-1122.

103. Cienfuegos JA, Rotellar F, Baixauli J, et al. Impact of perineural and lymphovascular invasion on oncological outcomes in rectal cancer treated with neoadjuvant chemoradiotherapy and surgery. Ann Surg Oncol 2015;22:916-923.

104. Belt EJ, van Stijn MF, Bril H, et al. Lymph node negative colorectal cancers with isolated tumor deposits should be classified and treated as stage III. Ann Surg Oncol 2010;17:3203-3211.

105. Yabata E, Udagawa M, Okamoto $H$. Effect of tumor deposits on overall survival in colorectal cancer patients with regional lymph node metastases. J Rural Med 2014;9:20-26.

106. Fleming ID, Cooper JS, Hensen DE, et al. AJCC Cancer Staging Manual. 5. Lippincott-Raven Publishers: Philadelphia, PA; 1997. pp.83-88.

107. Greene FL, Page DL, Fleming ID, et al. AJCC Cancer Staging Manual. 6. Springer-Verlag: New York, NY: 2002, pp. 113-124.

108. Nagtegaal ID, Quirke P. Colorectal tumour deposits in the mesorectum and pericolon; a critical review. Histopathology 2007;51:141-149.

109. Briedley JD, Gospodarowicz MK, Wittekind C (eds). TNM classification of malignant tumours, $8^{\text {th }}$ edition. Wiley-Blackwell; December 2016.

110. Rock JB, Washington MK, Adsay NV, et al. Debating deposits: an interobserver variability study of lymph nodes and pericolonic tumor deposits in colonic adenocarcinoma. Arch Pathol Lab Med 2014;138:636-642.

111. Nagtegaal ID, Knijn N, Hugen N, et al. Tumor deposits in colorectal cancer: improving the value of modern staging-A systematic review and meta-analysis. J Clin Oncol 2017;35:1119-1127.

112. Goldstein NS, Turner JR. Pericolonic tumor deposits in patients with $\mathrm{T} 3 \mathrm{~N}+\mathrm{MO}$ colon adenocarcinomas: markers of reduced disease free survival and intra-abdominal metastases and their implications for TNM classification. Cancer 2000;88:2228-2238.

113. Ueno H, Mochizuki H, Shirouzu K, et al; Study Group for Tumor Deposits without Lymph Node Structure in Colorectal Cancer projected by the Japanese Society for Cancer of the Colon and Rectum. Multicenter study for optimal categorization of 
extramural tumor deposits for colorectal cancer staging. Ann Surg 2012;255:739-746.

114. Gopal P, Lu P, Ayers GD, Herline AJ, Washington MK. Tumor deposits in rectal adenocarcinoma after neoadjuvant chemoradiation are associated with poor prognosis. Mod Pathol 2014;27:1281-1287.

115. Wei XL, Qiu MZ, Zhou YX, et al. The clinicopathologic relevance and prognostic value of tumor deposits and the applicability of N1c category in rectal cancer with preoperative radiotherapy. Oncotarget 2016;7:75094-75103.

116. Yang J, Xing S, Li J, et al. Novel lymph node ratio predicts prognosis of colorectal cancer patients after radical surgery when tumor deposits are counted as positive lymph nodes: a retrospective multicenter study. Oncotarget 2016;7:73865-73875.

117. Lord AC, D'Souza N, Pucher PH, et al. Significance of extranodal tumour deposits in colorectal cancer: A systematic review and meta-analysis. Eur J Cancer 2017;82:92-102.

118. Nagayoshi K, Ueki T, Nishioka Y, et al. Tumor deposit is a poor prognostic indicator for patients who have stage II and III colorectal cancer with fewer than 4 lymph node metastases but not for those with 4 or more. Dis Colon Rectum 2014;57:467-474.

119. Lin Q, Wei Y, Ren L, et al. Tumor deposit is a poor prognostic indicator in patients who underwent simultaneous resection for synchronous colorectal liver metastases. Onco Targets Ther 2015;8:233-240.

120. Jin M, Roth R, Rock JB, Washington MK, Lehman A, Frankel WL. The impact of tumor deposits on colonic adenocarcinoma AJCC
TNM staging and outcome. Am J Surg Pathol 2015;39:109-115.

121. Nagtegaal ID, Tot T, Jayne DG, et al. Lymph nodes, tumor deposits, and TNM: are we getting better? J Clin Oncol 2011;29:2487-2492.

122. Tong L, Gao P, Wang Z, et al. Is the seventh edition of the UICC/ AJCC TNM staging system reasonable for patients with tumor deposits in colorectal cancer? Ann Surg 2012;255:208-213.

123. Resch A, Langner C. Lymph node staging in colorectal cancer: old controversies and recent advances. World J Gastroenterol 2013;19:8515-8526.

124. Wind J, ten Kate FJ, Kiewiet JJ, et al. The prognostic significance of extracapsular lymph node involvement in node positive patients with colonic cancer. Eur J Surg Oncol 2008;34:390-396.

125. Cienfuegos JA, Baixauli J, Rotellar F, et al. Clinical significance of cellular and acellular mucin pools in rectal carcinoma following preoperative chemoradiotherapy. Clin Transl Oncol 2016;18:714721.

126. Bhatti AB, Akbar A, Khattak S, Kazmi AS, Jamshed A, Syed AA. Impact of acellular mucin pools on survival in patients with complete pathological response to neoadjuvant treatment in rectal cancer. Int J Surg 2014;12:1123-1126.

127. Shia J, McManus M, Guillem JG, et al. Significance of acellular mucin pools in rectal carcinoma after neoadjuvant chemoradiotherapy. Am J Surg Pathol 2011;35:127-134.

128. Lim SB, Hong SM, Yu CS, et al. Prevalence and clinical significance of acellular mucin in locally advanced rectal cancer patients showing pathologic complete response to preoperative chemoradiotherapy. Am J Surg Pathol 2013;37:47-52. 